$\overline{\text { Original }}$

\title{
Surface Treatment and Facilitated Cleaning of Stainless Steel by Ozonized Air
}

\author{
SATOSHI FUKUZAKI*, HIROMI URANO, MINORU HIRAMATSU, \\ AND ATSUHIKO TAKEHARA \\ Industrial Technology Center of Okayama Prefecture, 5301 Haga, Okayama 701-1296, Japan
}

Received 2 November 2000/Accepted 29 January 2001

\begin{abstract}
Surface treatment of stainless steel by ozonized air was investigated over the range of 0.01 to $0.2 \%(\mathrm{v} / \mathrm{v})$ ozone $\left(\mathrm{O}_{3}\right)$, using nonporous stainless steel particles. Ozonized air contained nitrogen oxides $\left(\mathrm{NO}_{\mathrm{x}}\right)$ at a $\mathrm{NO}_{\mathrm{x}} / \mathrm{O}_{3}$ ratio of approximately 0.04 . When stainless steel particles were treated with ozonized air, nitric acid was formed on their surfaces depending on the $\mathrm{O}_{3}$ concentration. As a result of ozonized air treatment, the adsorption affinity of water vapor for stainless steel particles decreased and the absolute values of the apparent surface charge density ( $\sigma_{\text {app }}$ ) of stainless steel particles decreased over the pH range of 3 to 10 , resulting in the lower adsorption affinity of bovine serum albumin (BSA). The $\sigma_{\text {app }}$ curves of stainless steel particles treated with ozonized air at 0.15 to $0.2 \% \mathrm{O}_{3}$ were very similar to the curves of the particles treated with 10 and $30 \% \mathrm{HNO}_{3}$. These results indicated that nitric acid formed during ozonized air treatment brought about the modification of the surface charge of stainless steel particles. Ozonized air pretreatment of stainless steel particles fouled with BSA or calcium hydrogenphosphate markedly facilitated their removal during subsequent alkali cleaning or rinsing through $\mathrm{O}_{3}$ oxidation or descaling with nitric acid.
\end{abstract}

Key words : Facilitated cleaning/Stainless steel/Ozonized air/Nitric acid/Surface treatment.

\section{INTRODUCTION}

In the food industry, products are often contaminated chemically and microbiologically from equipment surfaces during storage, transport, and processing. Cleanliness of product-contact surfaces is a very important issue in preventing contamination of the product processed. Food residues on product-contact surfaces that serve as nutrients for microorganisms should be removed by routine cleaning after each set of processing operations. In general, food residues on heated surfaces, e.g., milk deposits, consist of alkalisoluble (organic) and acid-soluble (inorganic) components (Burton, 1968; Lalande et al., 1984), and they are commonly removed by applying both alkaline and acidic detergents (Dunsmore et al., 1981; Jeurnink and Brinkman, 1994). Caustic solution is very

*Corresponding author. Tel : +81-86-286-9600, Fax : + 81-86-286-9630. effective and is widely used to clean equipment because of its excellent ability to solubilize a variety of organic substances. Alkaline detergent is composed mainly of sodium hydroxide, to which chlorinated compounds, phosphates, chelating agents, and surfactants are added in order to enhance the cleaning efficiency (Clegg, 1962; Graßhoff, 1988; Twomey, 1968). On the other hand, nitric acid, phosphoric acid, and organic acids are used for acid cleaning to dissolve mineral deposits. However, acidic solutions except for nitric acid and chlorine solution cause some corrosion to stainless steel, the material most widely used in the construction of food-processing equipment. Roughening the inner surface of stainless steel causes reduction of the cleaning efficiency (Timperley, 1981). In addition, the use of large quantities of detergent is fairly costly, and yields a high waste load for biological wastewater treatment.

Recently, ozone $\left(\mathrm{O}_{3}\right)$ has been increasingly used as an alternative oxidizing agent to chlorine. Ozone 
has a strong sterilizing ability and has been used successfully in drinking water treatment as a substitute for chlorine (Rice et al., 1981; Singer, 1990; Smith and Moss, 1993). Ozone is produced commercially from either oxygen or air by a silent surface discharge ozonizer. Ozonized oxygen generated from an oxygen-fed ozonizer consists only of oxygen species $\left(\mathrm{O}_{2}, \mathrm{O}_{3}\right.$, and $\left.\mathrm{O}\right)$ and it reacts with fouling deposits directly as molecular $\mathrm{O}_{3}$ or indirectly as ozone-derived free radicals. Our recent studies demonstrated that pretreatment with ozonized oxygen to aluminum oxide $\left(\mathrm{Al}_{2} \mathrm{O}_{3}\right)$ fouled with bovine serum albumin (BSA) markedly accelerated the removal of BSA during subsequent alkali cleaning through partial decomposition of the adsorbed BSA (Takehara et al., 2000; Urano and Fukuzaki, 2001). On the other hand, silent discharge in an air-fed ozonizer produces not only $\mathrm{O}_{3}$ but also small amounts of nitrogen oxides ( $\mathrm{NO}_{x}$ ) such as $\mathrm{NO}, \mathrm{NO}_{2}, \mathrm{NO}_{3}, \mathrm{~N}_{2} \mathrm{O}$, and $\mathrm{N}_{2} \mathrm{O}_{5}$ (Braun et al., 1990; Kogelschatz and Baessler, 1987; Yagi and Tanaka, 1979). Among $\mathrm{NO}_{x}$ components, dinitrogen pentoxide $\left(\mathrm{N}_{2} \mathrm{O}_{5}\right)$ is further transformed into nitric acid $\left(\mathrm{HNO}_{3}\right)$ through reaction with traces of $\mathrm{H}_{2} \mathrm{O}$ (Kogelschatz and Baessler, 1987). This suggests that treatment of solid surfaces including stainless steel by ozonized air, which contains both $\mathrm{O}_{3}$ and $\mathrm{NO}_{x}$, under atmospheric conditions would result in the formation of nitric acid on their surfaces. Nitric acid has so far been used for chemical passivation of stainless steel (Asami and Hashimoto, 1979) and for descaling (Twomey, 1968).

In the present study, the effectiveness of treatment of clean and fouled stainless steel with ozonized air was investigated and compared with that of treatments with ozonized oxygen and $\mathrm{HNO}_{3}$. We used nonporous stainless steel particles as a model material, and BSA and calcium hydrogenphosphate $\left(\mathrm{CaHPO}_{4}\right)$ as model fouling deposits. This paper describes how ozonized air treatment could modify the surface charge of stainless steel and facilitate cleaning of BSA-fouled and $\mathrm{CaHPO}_{4}$-fouled stainless steel owing to the action of $\mathrm{O}_{3}$ and nitric acid.

\section{MATERIALS AND METHODS}

\section{Materials and chemicals}

Nonporous stainless steel particles (SUS $316 \mathrm{~L}$ ), BSA (Fraction $\mathrm{V}$ ), and other chemicals (analytical grade) were the same as those described previously (Fukuzaki et al., 2001).

\section{Surface treatments of stainless steel particles}

Ozonized air was generated from dry air by a silent discharge ozonizer (Model 961; OHNIT Co. Ltd., Okayama) equipped with an ozone monitor (PG-320; Ebara Jitsugyo Co. Ltd., Tokyo). A 10-g aliquot of untreated stainless steel particles was placed in a cylindrical glass column $(28 \mathrm{~mm}$ diameter $\times 220 \mathrm{~mm}$ length) which was connected to the ozonizer device. Ozonized air ( 0.01 to $0.2 \%, \mathrm{v} / \mathrm{V}, \mathrm{O}_{3}$ ) was passed through the glass column at a flow rate of $5 \mathrm{l} / \mathrm{min}$ for $60 \mathrm{~min}$ at room temperature. Relative humidity in the glass column was not controlled. After the treatment, each 2-g aliquot portion of the ozonized air-treated stainless steel particles was transferred into a $25-\mathrm{ml}$ glass vial, and then rinsed three times with $10 \mathrm{ml}$ of deionized water $\left(40^{\circ} \mathrm{C}, 140\right.$ oscillations per min, $10 \mathrm{~min}$ ) by centrifugation $(2300 \times g$ for $1 \mathrm{~min})$. After being rinsed, the ozone-treated stainless steel particles were dried at $150^{\circ} \mathrm{C}$. Specific surface areas of ozonized air-treated stainless steel particles varied slightly between 0.40 (non-treated) and $0.50 \mathrm{~m}^{2} / \mathrm{g}$, depending on ozone concentrations. As a comparison, treatment of stainless steel particles with ozonized oxygen, generated from pure oxygen $(99.999 \%, \mathrm{v} / \mathrm{v})$, was also conducted at $\mathrm{O}_{3}$ concentration of $0.2 \%$ under the same conditions as those for ozonized air treatment.

Stainless steel particles were also treated with $\mathrm{HNO}_{3}$ solutions to compare the effects of nitric acid formed from the ozonized air treatment and $\mathrm{HNO}_{3}$ solution on the surface properties of stainless steel. Twenty-gram aliquots of non-treated stainless steel particles were put into $300-\mathrm{ml}$ flasks containing $200 \mathrm{ml}$ of $10 \%$ and $30 \% \mathrm{HNO}_{3}$ and treated for $1 \mathrm{~h}$ at $60{ }^{\circ} \mathrm{C}$. After $\mathrm{HNO}_{3}$ treatments, $\mathrm{HNO}_{3}$ solutions were carefully decanted, and the particles were suspended in $200 \mathrm{ml}$ of deionized water. The suspensions were then transferred into 500-ml centrifugation tubes and rinsed 10 times each with $300 \mathrm{ml}$ of deionized water by centrifugation $(1700 \times g$ for $5 \mathrm{~min})$. After being rinsed, the particles were dried at $150^{\circ} \mathrm{C}$. Specific surface areas of the particles treated with $10 \%$ and $30 \% \mathrm{HNO}_{3}$ were 0.49 , and $0.59 \mathrm{~m}^{2} / \mathrm{g}$, respectively.

In all surface treatments, three replicate samples were prepared per concentration of $\mathrm{O}_{3}$ and $\mathrm{HNO}_{3}$.

\section{X-ray photoelectron spectroscopic (XPS) analy- sis}

The chemical composition of the outermost surfaces of stainless steel particles was determined by XPS analysis. XPS analysis was performed on JPS90MX MICRO spectrometer (JEOL Ltd., Tokyo) using a $\mathrm{MgK}_{\alpha}(1253.6 \mathrm{eV})$ X-ray source (10kV and $\left.20 \mathrm{~mA}\right)$. The residual pressure in the spectrometer during data acquisition was always lower than $5 \times 10^{-7} \mathrm{~Pa}$. For the analysis, stainless steel particles were molded into a plate $(13 \mathrm{~mm}$ diameter $\times 1 \mathrm{~mm}$ thickness) by compression (40 MPa, 2min). The pellet obtained was then transferred into the high vacuum chamber of the XPS instruments and allowed to stand for $24 \mathrm{~h}$. No argon ion etching was performed. The measured spectra 
were $\mathrm{Fe} 2 \mathrm{p} 3 / 2$, $\mathrm{Cr} 2 \mathrm{p} 3 / 2$, Ni 2p3/2, O 1s, and C 1s, and the quantification of the elements was based on the area intensity and atomic percentage. To compensate for sample charging during the analysis all the binding energies were referred to the $C 1$ s signal at $284.7 \mathrm{eV}$.

\section{Water vapor adsorption and surface charge measurements}

Measurement of the isotherm of water vapor adsorption onto stainless steel surfaces $\left(25^{\circ} \mathrm{C}\right)$ and BET analysis of the isotherm were carried out as described previously (Fukuzaki et al., 2001). The apparent surface charge density $\left(\sigma_{\text {app }}\right.$ ) and apparent point of zero charge $\left(\mathrm{pzC}_{\mathrm{app}}\right)$ of stainless steel particles were determined by potentiometric titration as described previously (Fukuzaki et al., 2001). The measurements of the water adsorption isotherms and the $\sigma_{\text {app }}$ curves were carried out for each of the three replicate samples per treatment.

\section{Fouling experiments}

Adsorption of BSA on stainless steel particles (40 ${ }^{\circ} \mathrm{C}$ ) and determination of the amount of BSA adsorbed $\left(\Gamma_{\mathrm{BSA}}\right)$ were carried out as described previously (Fukuzaki, et al., 2001). To determine the effect of surface treatment of stainless steel particles on $\Gamma_{\text {BSA, }}$ each adsorption experiment was replicated three times for each of the surface-treated particles.

The $\mathrm{CaHPO}_{4}$-fouled stainless steel particles were prepared at $25^{\circ} \mathrm{C}$ as follows. A 2-g aliquot of untreated stainless steel particles was put into a $100-\mathrm{ml}$ flask containing $50 \mathrm{ml}$ of $\mathrm{CaHPO}_{4}$ solution (5.6mM, pH4.0). By adding $4.5 \mathrm{ml}$ of $0.1 \mathrm{M} \mathrm{KOH}$ into the suspension, $\mathrm{CaHPO}_{4}$ precipitate was deposited on stainless steel particles with agitation at $200 \mathrm{rpm}$ for $10 \mathrm{~min}$. After agitation, the $\mathrm{CaHPO}_{4}$-fouled particles were collected by centrifugation $(2300 \times g, 1 \mathrm{~min})$, and the collected particles were washed twice with $50 \mathrm{ml}$ of deionized water, also by centrifugation $(2300 \times g, 1 \mathrm{~min})$. The amount of deposited $\mathrm{CaHPO}_{4}\left(\Gamma_{\mathrm{CaHPO}}\right)$ was calculated from the amount of $\mathrm{Ca}$ removed after treatment with $0.1 \mathrm{M} \mathrm{HNO}_{3}$ at $40^{\circ} \mathrm{C}$ for $2 \mathrm{~h}$.

\section{Cleaning experiments}

To determine the effect of ozone pretreatment on cleaning, $4.0 \mathrm{~g}$ of BSA-fouled particles $\left(\Gamma_{\mathrm{BSA}}=\mathrm{ca}\right.$. 2.0 $\mathrm{mg} / \mathrm{m}^{2}$ ) and $0.5 \mathrm{~g}$ of $\mathrm{CaHPO}_{4}$-fouled particles ( $\Gamma_{\text {CaHPO4 }}$ $=$ ca. $66 \mathrm{mg} / \mathrm{m}^{2}$ ) were pretreated with ozonized air or ozonized oxygen at $0.2 \%(\mathrm{v} / \mathrm{v}) \mathrm{O}_{3}$ for $30 \mathrm{~min}$, respectively.

The time course of BSA desorption from stainless steel surfaces was determined during repeated-batch cleaning at $40^{\circ} \mathrm{C}$ as described previously (Fukuzaki et al., 2001). A 4.0-g aliquot of BSA-fouled stainless

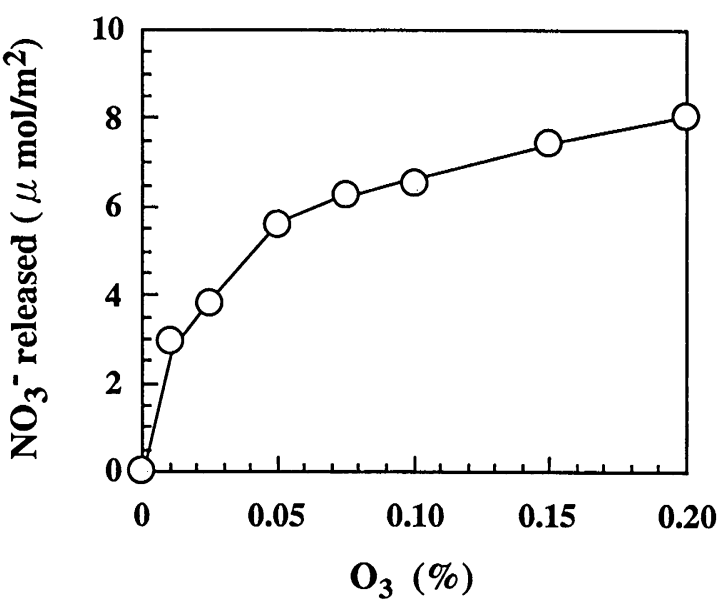

FIG. 1 . Concentration of nitrate ions released from ozonized air-treated stainless steel particles during rinsing. A 2-g aliquot of ozonized air-treated stainless steel particles was rinsed with $10 \mathrm{ml}$ of deionized water $\left(25^{\circ} \mathrm{C}\right)$ in a $25-\mathrm{ml}$ glass vial with shaking (140 oscillations per min) for $10 \mathrm{~min}$.

steel particles was cleaned using $10 \mathrm{ml}$ of deionized water ( $\mathrm{pH} 5.7)$ for $50 \mathrm{~min}$ followed by the use of $0.01 \mathrm{M}$ $\mathrm{NaOH}$ for $180 \mathrm{~min}$. The headspace of the vial was replaced by $\mathrm{N}_{2}$ gas throughout cleaning experiment. The BSA desorption curve was obtained by plotting the logarithm of the amount of BSA remaining at time $t(S)$ relative to that immediately before alkali cleaning $\left(S_{0}=\Gamma_{\mathrm{BSA}}\right), \ln S / S_{0}$, against cumulative cleaning time.

Cleaning of $\mathrm{CaHPO}_{4}$-fouled stainless steel particles was also conducted in a batchwise manner by introducing $0.5 \mathrm{~g}$ of $\mathrm{CaHPO}_{4}$-fouled particles and $10 \mathrm{ml}$ of deionized water or $0.1 \mathrm{M} \mathrm{HNO}_{3}$ in a $25-\mathrm{ml}$ glass vial, which was then reciprocally shaken at $40^{\circ} \mathrm{C}$ for $2 \mathrm{~h}$.

\section{Analytical procedures}

Nitrate $\left(\mathrm{NO}_{3}^{-}\right)$was analyzed with an ion chromatograph (2010i; DIONEX, Osaka) equipped with an IonPac AS4A-SC column and an electric conductivity detector. The column was operated with $40 \mathrm{mM} \mathrm{KOH}$ at a flow rate of $1.0 \mathrm{ml} / \mathrm{min}$. $\mathrm{NO}_{\mathrm{x}}$ in ozonized air was measured by an $\mathrm{NO}_{x}$ analyzer (CLA-510SS, Horiba Ltd., Tokyo) with NO gas as the standard. BSA (nonozone-treated and ozone-treated) was measured using the Lowry-Folin method as described previously (Urano and Fukuzaki, 2001). The amounts of iron, chromium, nickel, and calcium were measured by using an inductively coupled plasma (ICP) spectrometer as described previously (Fukuzaki et al., 1995).

\section{RESULTS AND DISCUSSION}

\section{Formation of nitric acid on stainless steel sur- faces}


TABLE 1 . Atomic composition of the outermost surfaces of stainless steel particles treated with ozonized air, ozonized oxygen, and $\mathrm{HNO}_{3}$ solutions.

\begin{tabular}{lllcc}
\hline \multirow{2}{*}{ Stainless steel } & \multicolumn{4}{c}{ Component (atom \%) } \\
\cline { 2 - 5 } & $\mathrm{Cr}$ & $\mathrm{Fe}$ & $\mathrm{O}$ & $\mathrm{C}$ \\
\hline Non-treated & 3.6 & 4.2 & 54.7 & 23.5 \\
Ozonized air-treated & 4.0 & 3.0 & 52.8 & 23.8 \\
Ozonized oxygen-treated & 3.3 & 3.5 & 51.9 & 22.7 \\
$10 \% \mathrm{HNO}_{3}$-treated & 8.6 & 2.2 & 51.7 & 22.1 \\
$30 \% \mathrm{HNO}_{3}$-treated & 8.9 & 1.9 & 54.2 & 21.9 \\
\hline
\end{tabular}

Stainless steel particles were treated with ozonized air and ozonized oxygen at $0.2 \% \mathrm{O}_{3}$ for $1 \mathrm{~h}$ at room temperature. Argon ion etching was not conducted. Another major spectrum was observed at $101.7 \mathrm{eV}$ which assigned to Si $2 \mathrm{p}$.

Stainless steel particles were treated with ozonized air at $\mathrm{O}_{3}$ concentrations of 0.01 to $0.2 \%(\mathrm{v} / \mathrm{v})$, in which $\mathrm{NO}_{x}$ species were contained at $\mathrm{NO}_{x} / \mathrm{O}_{3}$ ratio of approximately 0.04 (data not shown). When all the ozonized air-treated stainless steel particles were rinsed with deionized water, $\mathrm{NO}_{3}^{-}$was detected in the rinse water. Figure 1 shows concentration of $\mathrm{NO}_{3}^{-}$released in rinse water as a function of $\mathrm{O}_{3}$ concentration. $\mathrm{NO}_{3}^{-}$concentration increased with increasing concentrations of $\mathrm{O}_{3}$ and hence of $\mathrm{NO}_{x}$, with a maximum value of approximately $8.0 \mu \mathrm{mol} / \mathrm{m}^{2}$. This suggested that nitric acid was formed on stainless steel surfaces during ozonized air treatment. It has been reported that the $\mathrm{NO}_{x}$ formed in the silent discharge of

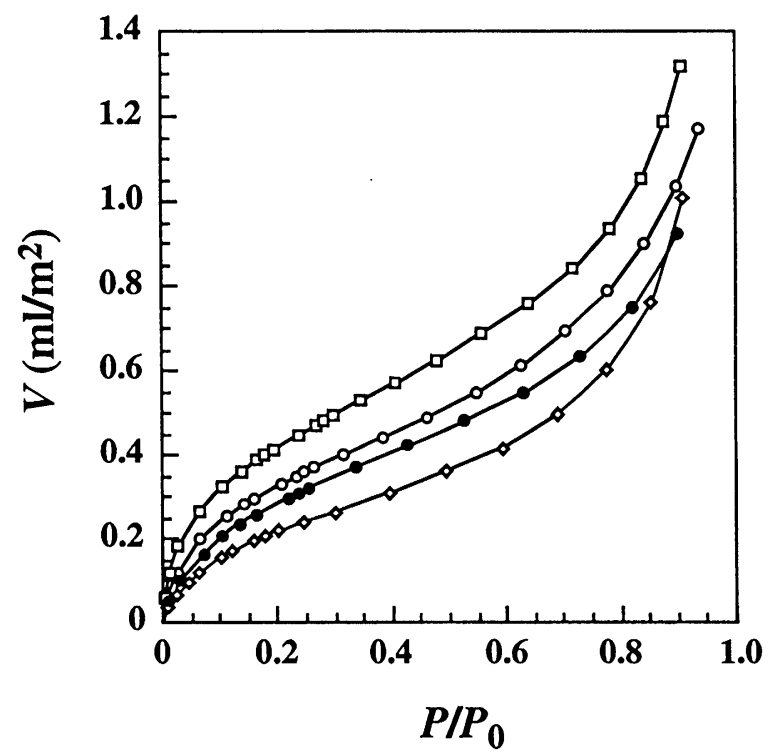

FIG. 2. Isotherms of water vapor adsorption on non-treated, ozonized air-treated, and $30 \% \mathrm{HNO}_{3}$-treated stainless steel particles at $25^{\circ} \mathrm{C}$. Stainless steel particles were treated with Ozonized air at $0.2 \%$ (vol/vol) $\mathrm{O}_{3}$. Symbols: $\bigcirc$, non-treated particles; $\square$, ozonized air-treated particles before rinsing , ozonized air-treated particles after rinsing; $\diamond, 30 \%$ $\mathrm{HNO}_{3}$-treated particles. an air-fed ozonizer played an important role in the catalytic cycle of $\mathrm{O}_{3}$ destruction (Yagi and Tanaka, 1979) and that $\mathrm{NO}_{x}$ species were transformed into nitric acid via the formation of $\mathrm{N}_{2} \mathrm{O}_{5}$ in the presence of $\mathrm{O}_{3}$ and $\mathrm{H}_{2} \mathrm{O}$ (Kogelschatz and Baessler, 1987). According to previous reports (Yagi and Tanaka, 1979; Kogelschatz and Baessler, 1987), the following mechanism is proposed for the predominant pathway of nitric acid formation during ozonized air treatment:

$$
\begin{aligned}
& \mathrm{NO}+\mathrm{O}_{3} \rightarrow \mathrm{NO}_{2}+\mathrm{O}_{2} \\
& \mathrm{NO}_{2}+\mathrm{O}_{3} \rightarrow \mathrm{NO}_{3}+\mathrm{O}_{2} \\
& \mathrm{NO}_{2}+\mathrm{NO}_{3} \rightarrow \mathrm{N}_{2} \mathrm{O}_{5} \\
& \mathrm{~N}_{2} \mathrm{O}_{5}+\mathrm{H}_{2} \mathrm{O} \rightarrow 2 \mathrm{HNO}_{3}
\end{aligned}
$$

It is conceivable that water molecules physisorbed on stainless steel surfaces were involved in the reaction with $\mathrm{N}_{2} \mathrm{O}_{5}$.

\section{Characterization of outermost surfaces of ozonized air-treated stainless steel}

Table 1 shows the atomic composition of main

TABLE 2. BET equation constants for the adsorption of water vapor onto the stainless steel particles treated with ozonized air, ozonized oxygen, and $\mathrm{HNO}_{3}$ solutions.

\begin{tabular}{lcc}
\hline \multicolumn{1}{c}{ Stainless steel } & $V_{\mathrm{m}}\left(\mathrm{ml} / \mathrm{m}^{2}\right)$ & $c(-)$ \\
\hline Non-treated & 0.32 & 26.3 \\
Ozonized air-treated & & \\
with rinse & 0.26 & 18.5 \\
$\quad$ without rinse & 0.37 & 28.9 \\
Ozonized oxygen-treated & 0.28 & 24.8 \\
10\% $\mathrm{HNO}_{3}$-treated & 0.22 & 18.3 \\
$30 \% \mathrm{HNO}_{3}$-treated & 0.21 & 16.1 \\
\hline
\end{tabular}

Stainless steel particles were treated with ozonized air and ozonized oxygen at $0.2 \% \mathrm{O}_{3}$ for $1 \mathrm{~h}$ at room temperature. The constants were derived from linear regression fits of the BET equation to the water vapor adsorption data in the $P / P_{0}$ range of 0.05 to 0.30 . 


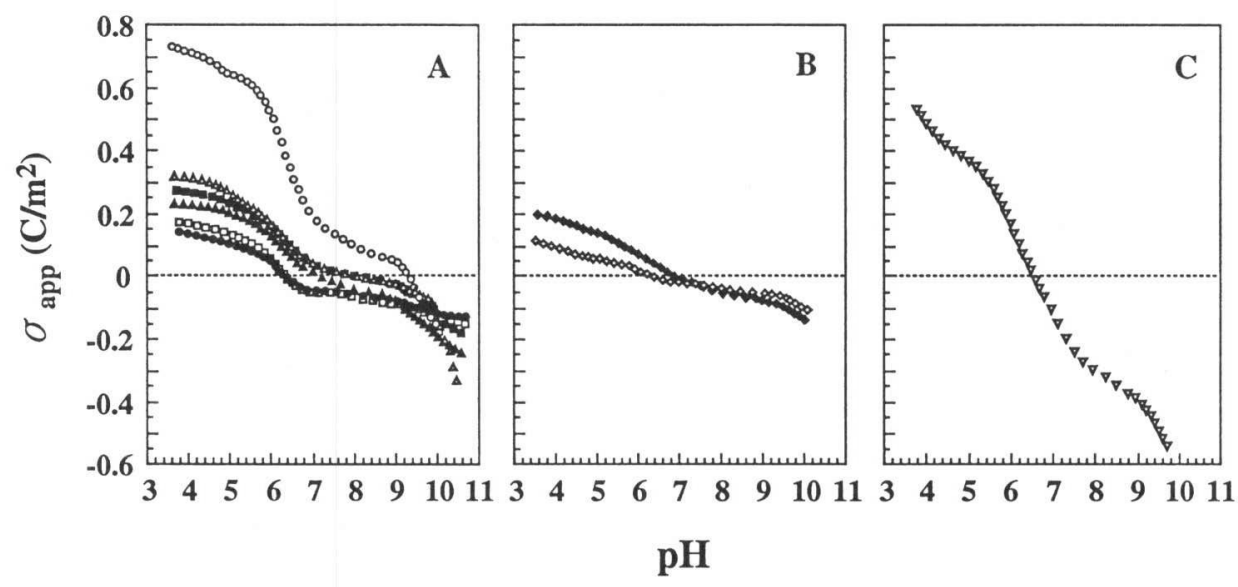

FIG.3. $\sigma_{\text {app }}$ curves of non-treated, ozonized air treated, $\mathrm{HNO}_{3}$-treated, and ozonized oxygen-treated stainless steel particles as a function of $\mathrm{pH}$. Potentiometric titration was conducted in $10^{-3} \mathrm{M} \mathrm{KNO}_{3}$ solution. Symbols: (A) O, non-treated particles; $\triangle$, ozonized air-treated particles $\left(0.02 \% \mathrm{O}_{3}\right) ; \mathbf{D}$, ozonized air-treated particles $\left(0.05 \% \mathrm{O}_{3}\right) ; \boldsymbol{\Delta}$, ozonized air-treated particles $\left(0.1 \% \mathrm{O}_{3}\right)$ ozone; $\square$, ozonized air-treated particles $\left(0.15 \% \mathrm{O}_{3}\right) ; \mathbf{O}$, ozonized air-treated particles $\left(0.2 \% \mathrm{O}_{3}\right) ;(\mathrm{B})$ $\mathrm{HNO}_{3}$-treated particles; $\diamond, 30 \% \mathrm{HNO}_{3}$-treated particles; (C) $\nabla$, ozonized oxygen-treated particles $\left(0.2 \% \mathrm{O}_{3}\right)$.

metal components of the outermost surfaces of stainless steel particles treated with ozonized air ( $0.2 \%$ $\mathrm{O}_{3}$ ), ozonized oxygen $\left(0.2 \% \mathrm{O}_{3}\right)$, and $\mathrm{HNO}_{3}$ solutions. The ozonized air treatment showed a slight increase in the atomic ratio of chromium to iron in the outermost surfaces, whereas no significant change in the chromium/iron ratio was observed in ozonized oxygen-treated stainless steel. Treatments with 10\% and $30 \% \mathrm{HNO}_{3}$ resulted in the significant enrichment of chromium in the surfaces. These results indicated that the nitric acid formed during ozonized air treatment could contribute to a slight increase in chromium content. The $10 \%$ and $30 \% \mathrm{HNO}_{3}$ treatments lead to enrichment of chromium throughout the passive film on stainless steel (Asami and Hashimoto, 1979), whereas ozonized air treatment appears to modify only a very thin layer of the passive film on stainless steel. No significant amount of nickel was detected in the outermost surfaces of all the stainless steel.

To assess the variation in the surface hydroxyl groups $(\mathrm{M}-\mathrm{OH})$ on stainless steel particles by surface treatments, isotherms of water vapor adsorption on stainless steel particles were measured. Figure 2 shows the isotherms for water vapor adsorption on non-treated particles, ozonized air-treated particles at $0.2 \% \mathrm{O}_{3}$ before and after rinsing, and 30\% $\mathrm{HNO}_{3}$ treated particles. The amounts of water vapor adsorbed $(V)$ were plotted against the relative vapor pressure $\left(P / P_{0}\right)$, where $P$ and $P_{0}$ are the equilibrium and saturated vapor pressures, respectively. The ozonized air-treated particles without rinsing apparently exhibited a higher affinity for water than the nontreated particles. This is evidently due to the presence of nitric acid that is hygroscopic on the stainless steel surfaces. On the other hand, the isotherm on the rinsed ozonized air-treated particles was characterized by a lower affinity for water. The 30\% $\mathrm{HNO}_{3}$-treated particles showed a much lower affinity for water. Table 2 shows the results of BET analysis of the isotherms on the particles obtained by the all surface treatments in the low $P / P_{0}$ range of 0.05 to 0.3. The monolayer saturation amounts $\left(V_{\mathrm{m}}\right)$ and BET $c$ values, reflecting the adsorption affinity, were considerably lower for the particles treated with $10 \%$ and $30 \% \mathrm{HNO}_{3}$ than those for non-treated particles. Ozonized air treatment (with rinsing) also resulted in the relatively lower $V_{\mathrm{m}}$ and BET $c$ values compared with those for ozonized oxygen-treated particles and non-treated particles. These results indicate that nitric acid formed during ozonized air treatment was responsible for a decrease in the number of adsorption sites for water vapor, i.e., hydroxyl groups, on stain-
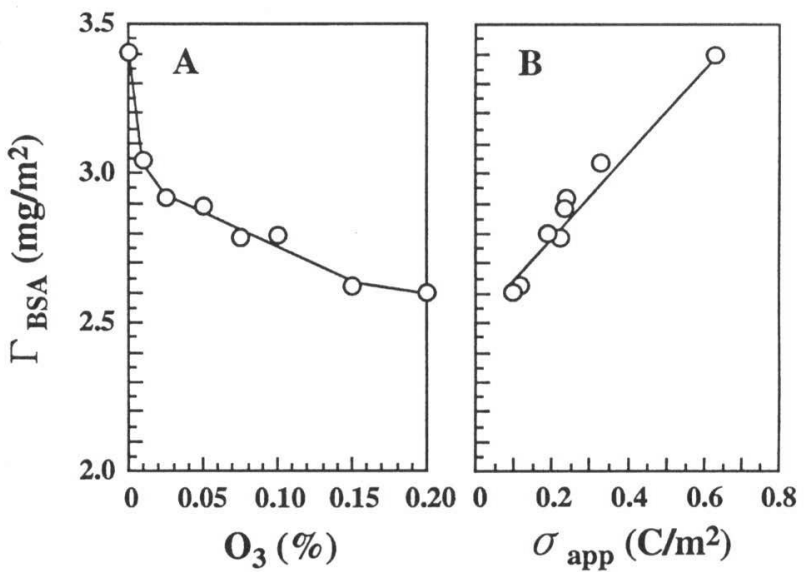

FIG. 4. $\Gamma_{\text {BSA }}$ on ozonized air-treated stainless steel particles at $\mathrm{O}_{3}$ concentrations of 0.01 to $0.2 \%(\mathrm{v} / \mathrm{v})$. The adsorption experiment was conducted in a $25-\mathrm{ml}$ glass vial at $40^{\circ} \mathrm{C}$ and at pH5.2. (A) $\Gamma_{\text {BSA }}$ as a function of $\mathrm{O}_{3}$ concentration; (B) $\Gamma_{\text {BSA }}$ as a function of $\sigma_{\text {app }}$ at pH5.2. 
less steel surfaces. In connection with this, Asami and Hashimoto (1979) have reported that treatments of type 304 and 316 stainless steel with $10 \%$ and $30 \%$ $\mathrm{HNO}_{3}$ gave smaller ratios of oxygen in $\mathrm{M}-\mathrm{OH}$ to the total amount of oxygen (oxygen in $\mathrm{M}-\mathrm{OH}$ plus oxygen in $\mathrm{M}-\mathrm{O}-\mathrm{M}$ ) in the surface films, suggesting that the $\mathrm{OH}$-type oxygen in the surface film was transformed into the MOM-type oxygen.

Since the surface charge of oxide and stainless steel is established by the protonation $\left(\mathrm{M}-\mathrm{OH}_{2}^{+}\right)$or deprotonation $\left(\mathrm{M}-\mathrm{O}^{-}\right.$) of surface hydroxyl groups (Fukuzaki et. al., 1998; Parks and Bruym, 1962), varying the degree of surface hydroxylation gives rise to the change in the electrostatic nature of stainless steel particles. Figure 3 shows the representative $\sigma_{\text {app }}$ curves of non-treated, ozonized air-treated, ozonized oxygen-treated, and $\mathrm{HNO}_{3}$-treated stainless steel particles as a function of $\mathrm{pH}$. The $\mathrm{pzc}_{\mathrm{app}}$ of the non-treated particles was found to be 9.2. The pzc' $S_{\text {app }}$ of ozonized air-treated particles were situated at points corresponding to more acidic $\mathrm{pH}$ values than the $\mathrm{pzc}_{\mathrm{app}}$ of the non-treated particles (Fig. 3A). The degrees of the shift in the pzc $\mathrm{c}_{\mathrm{app}}$ and of decrease in the absolute values of $\sigma_{\text {app }}$ depended on ozone concentration. The absolute values of $\sigma_{\text {app }}$ of $10 \%$ and $30 \%$ $\mathrm{HNO}_{3}$-treated particles were very low over the $\mathrm{pH}$ range of 3 to 10 , indicating the formation of electrostatically inert surfaces (Fig. 3B). The $\sigma_{\text {app }}$ curves of the ozonized air-treated particles at 0.15 to $0.2 \% \quad \mathrm{O}_{3}$, giving the

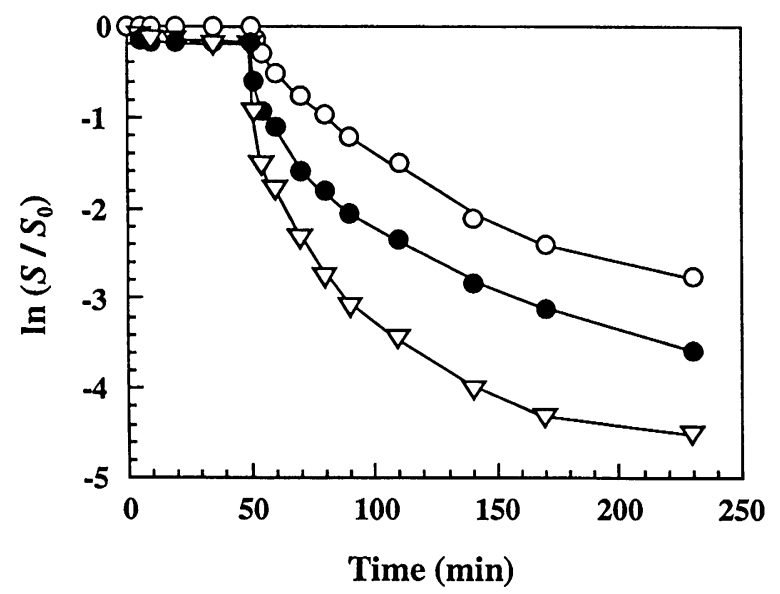

FIG.5. Time courses of BSA desorption from stainless steel particles during cleaning with $0.01 \mathrm{M} \mathrm{NaOH}$ with and without ozone pretreatment. The cleaning experiment was conducted in a $25-\mathrm{ml}$ glass vial at $40^{\circ} \mathrm{C}$ with reciprocal shaking (140 oscillations per $\mathrm{min}$ ) by a repeated-batch procedure. BSA-fouled stainless steel particles were pretreated with ozonized air or ozonized oxygen at $0.2 \%(\mathrm{v} / \mathrm{v}) \mathrm{O}_{3}$ for $30 \mathrm{~min}$, and cleaned using deionized water for $50 \mathrm{~min}$ followed by using the $\mathrm{NaOH}$ solution for $180 \mathrm{~min}$. Symbols: $\bigcirc$, alkali cleaning alone; $\boldsymbol{O}$, pretreated with ozonized air; $\nabla$, pretreated with ozonized oxygen.
TABLE 3. Effect of pretreatment with ozonized air on the removal of $\mathrm{CaHPO}_{4}$ deposited on stainless steel particles.

\begin{tabular}{lcc}
\hline \multirow{2}{*}{ Cleaning } & \multicolumn{2}{c}{ Ca removed } \\
\cline { 2 - 3 } & $\left(\mathrm{mg} / \mathrm{m}^{2}\right)$ & $(\%)$ \\
\hline $0.1 \mathrm{M} \mathrm{HNO}_{3}$ & 19.6 & 100 \\
$\mathrm{H}_{2} \mathrm{O}$ alone & 0.4 & 2.0 \\
$\mathrm{H}_{2} \mathrm{O}+$ pretreatment & 7.4 & 37.8 \\
$\quad$ with ozonized air & & \\
$\mathrm{H}_{2} \mathrm{O}+$ pretreatment & 0.9 & 4.6 \\
$\quad$ with ozonized oxygen & & \\
\hline
\end{tabular}

The $\mathrm{CaHPO}_{4}$-fouled stainless steel particles were washed with $0.1 \mathrm{M} \mathrm{HNO}_{3}$ or deionized water with and without pretreatment with ozonized air or ozonized oxygen at $0.2 \%$ $\mathrm{O}_{3}$ for $30 \mathrm{~min}$ at room temperature.

$\mathrm{pzC}_{\mathrm{app}}$ of 6.3 , were similar to the curves of $10 \%$ and $30 \% \mathrm{HNO}_{3}$-treated particles. The $\mathrm{pzC}_{\text {app }}$ was also lowered to 6.5 by treatment with ozonized oxygen at $0.2 \% \mathrm{O}_{3}$ whereas the absolute values of $\sigma_{\text {app }}$ were relatively higher compared with those from the curves of ozonized air-treated particles at $0.2 \% \mathrm{O}_{3}$ (Fig.3C). The difference between the $\sigma_{\text {app }}$ curves of the particles treated with ozonized air and ozonized oxygen at $0.2 \% \mathrm{O}_{3}$ could be interpreted as arising from the action of the nitric acid formed during ozonized air treatment.

\section{BSA adsorption on ozonized air-treated stainless steels}

To minimize the effects of electrostatic interaction between BSA molecules on their adsorption, BSA adsorption was conducted at the pzc $\mathrm{p}_{\text {app }}$ of BSA (pH5.2). Figure 4 shows $\Gamma_{\text {BSA }}$ values on ozonized air-treated stainless steel particles. The $\Gamma_{\text {BSA }}$ decreased gradually from 3.4 to $2.6 \mathrm{mg} / \mathrm{m}^{2}$ with increasing $\mathrm{O}_{3}$ concentration from 0.01 to $0.2 \%$ (Fig. $4 \mathrm{~A}$ ). The $\Gamma_{\mathrm{BSA}}$ values as a function of the $\sigma_{\text {app }}$ of stainless steel particles at pH5.2 are shown in Fig.4B. An approximate linear correlation between $\Gamma_{\text {BSA }}$ and $\sigma_{\text {app }}$ was observed, which is in good agreement with the results obtained for $\Gamma_{\text {BSA }}$ on the ozonized oxygen-treated stainless steel particles (Fukuzaki et al., 2001). The $\Gamma_{\text {BSA }}$ on the $10 \%$ and $30 \% \mathrm{HNO}_{3}$-treated particles were 2.5 and $2.3 \mathrm{mg} / \mathrm{m}^{2}$, respectively. Obviously, $\Gamma_{\text {BSA }}$ depends on the $\sigma_{\text {app }}$ of stainless steel particles. On positively charged solid surfaces, BSA is reported to be electrostatically adsorbed via carboxyl groups on the molecule (Fukuzaki et al., 1998; Urano and Fukuzaki, 2000). The decrease in $\Gamma_{B S A}$ on the ozonized airtreated stainless steel was probably due to the decrease in the number of adsorption sites, i.e., protonated hydroxyl groups, on stainless steel surfaces for carboxyl groups on the BSA molecule. 


\section{Effect of pretreatment of fouled stainless steel particles by ozonized air}

The effect of pretreatment of BSA-fouled stainless steel particles by ozonized air on the efficiency of alkali cleaning was examined and compared with that of ozonized oxygen pretreatment. Figure 5 shows the desorption curves of BSA during alkali cleaning after pretreatment with ozonized air or ozonized oxygen at $0.2 \% \mathrm{O}_{3}$ for $30 \mathrm{~min}$. By pretreatment with ozonized air or ozonized oxygen, small amounts of BSA were desorbed during rinsing and the removal of BSA was accelerated markedly during subsequent alkali cleaning. Probably, the acceleration of alkali cleaning could be attributed to partial decomposition of the BSA molecule into low-molecular fragments by $\mathrm{O}_{3}$ (Urano and Fukuzaki, 2001). Pretreatment with ozonized oxygen was found to be more effective on BSA removal than that with ozonized air. It is presumed that the nitric acid formed might induce the acid-denaturation of the BSA molecule or diminish the alkalinity of a lowconcentration $\mathrm{NaOH}$ solution $(0.01 \mathrm{M})$ to some extent, thereby causing a slight decrease in the solubility of $\mathrm{BSA}$ in the $\mathrm{NaOH}$ solution.

Table 3 shows the effect of pretreatment of $\mathrm{CaHPO}_{4}$-fouled stainless steel particles by ozonized air on their cleanability. The deposited $\mathrm{CaHPO}_{4}$ was completely removed by cleaning with $0.1 \mathrm{M} \mathrm{HNO}_{3}$. Ozonized air pretreatment resulted in the removal of a large amount of $\mathrm{CaHPO}_{4}$ only by rinsing with deionized water. This result indicated that nitric acid formed was responsible for the dissolution of the deposited $\mathrm{CaHPO}_{4}$ into the rinse water. On the other hand, only small amounts of $\mathrm{CaHPO}_{4}$ were removed both by rinsing alone and by that combined with ozonized oxygen pretreatment. Thus, the effects of pretreatment with ozonized air and ozonized oxygen are different for the organic and inorganic deposits due to the formation of nitric acid.

The results presented in this paper show that ozone $\left(\mathrm{O}_{3}\right)$ and small amounts of nitric acid formed during ozonized air treatment could contribute both to the formation of electrostatically inert surfaces and to facilitated removal of protein and mineral deposits on stainless steel.

\section{REFERENCES}

Asami, K., and Hashimoto, K. (1979) An X-ray photoelectron spectroscopic study of surface treatments of stainless steels. Crros. Sci., 19, 1007-1017.

Braun, D., Kuchler, U., and Pietsch, G. (1990) Aspects of ozone generation from air. Ozone Sci. Eng., 12, 255-268.

Burton, $\mathrm{H}$. (1968) Reviews of the progress of dairy science. Section G. Deposits from whole milk in heat treatment plant-A review and discussion. J. Dairy Res., 35, 317-
330.

Clegg, L. F. L. (1962) Cleaning and sterilization of milking equipment on the farm. In Milk Hygiene (F.A.O./W.H.O.), p.195-220, World Health Organization, Geneva.

Dunsmore, D. G., Twomey, A., Whittlestone, W. G., and Morgan, H. W. (1981) Design and performance of systems for cleaning product-contact surfaces of food equipment: a review. J. Food Prot., 44, 220-240.

Fukuzaki, S., Nishio, N., and Nagai, S. (1995) High rate performance and characterization of granular methanogenic sludges in upflow anaerobic sludge blanket reactors fed with various defined substrates. J. Ferment. Bioeng., 79, 354-359.

Fukuzaki, S., Urano, H., and Hiramatsu, M. (1998) Variation in the surface charge of stainless steel by surface treatment: role of surface hydroxyl groups. J. Surface Finish. Soc. Jpn., 49, 915-916.

Fukuzaki, S., Urano, H., and Hiramatsu, M. (1998) Study of the conformation of protein adsorbed on stainless steel surfaces. J. Surface Finish. Soc. Jpn., 49, 1237-1238.

Fukuzaki, S., Urano, H., Hiramatsu, M., and Takehara, A. (2001) Effect of ozone on the surface charge and cleanability of stainless steel. Biocontrol Sci., 6, 87-94.

Gra $\beta$ hoff, A. (1988) Zum Einflu $\beta$ der chemischen Komponenten alkalischer Reiniger auf die Kinetik der Ablosung festverkrusteter Belage aus Milchbestandteilen von Erhitzerplatten. Kieler Milchw. Forsch., 40, 139-177.

Jeurnink, T. J. M., and Brinkman, D. W. (1994) The cleaning of heat exchangers and evaporators after milk or whey. Int. Dairy J., 4, 347-368.

Kogelschatz, U., and Baessler, P. (1987) Determination of nitrous oxide and dinitrogen pentoxide concentrations in the output of air-fed ozone generators of high power density. Ozone Sci. Eng., 9, 195-206.

Lalande, M., Tissier, J.-P., and Corrieu, G. (1984) Fouling of a plate heat exchanger used in ultra-high-temperature sterilization of milk. J. Dairy Res., 51, 557-568.

Lowry, O. H., Rosenbrough, N. J., Farr, A. L., and Randall, R. J. (1951) Protein measurement with the Folin phenol reagent. J. Biol. Chem., 193, 265-275.

Parks, G. A., and Bruyn, P. L. (1962) The zero point of charge of oxides. J. Phys. Chem., 66, 967-973.

Singer, P. C. (1990) Assessing ozonation research needs in water treatment. J. Am. Water Works Assoc., 82, 78-88.

Takehara, A., Urano, H., and Fukuzaki, S. (2000) Effect of ozone pretreatment on alkali cleaning of alumina fouled with bovine serum albumin. J. Biosci. Bioeng., 89, 267270.

Timperley, D. A. (1981) Modern cleaning and recovery systems and techniques. J. Soc. Dairy Technol., 34, 6-14.

Twomey, A. (1968) The physics and chemistry of cleaning. N.Z. J. Dairy Technol., 3, 150-159.

Urano, H., and Fukuzaki, S. (2000) Conformation of adsorbed bovine serum albumin governing its desorption behavior at alumina-water interfaces. J. Biosci. Bioeng., 90, 105-111.

Urano, H., and Fukuzaki, S. (2001) Facilitation of cleaning of alumina surfaces fouled with heat-treated bovine serum albumin by ozone treatment. J. Food Prot., 64, 108-112.

Yagi, S., and Tanaka, M. (1979) Mechanism of ozone generation in air-fed ozonisers. J. Phys. D. Appl. Phys., 12, 1509-1520. 